\title{
AL-AWQAF
}

Jurnal Wakaf dan Ekonomi Islam

Vol. 13, No. 1, Tahun 2020

\section{Analisis Faktor-Faktor yang Memengaruhi Kepuasan Wakif terhadap Pelayanan Lembaga Wakaf}

\author{
Muhammad Wicaksono Hasdyani Putra ${ }^{1}$, Tika Widiastuti ${ }^{2}$, Effendie $^{3}$ \\ ${ }^{1}$ Universitas Airlangga, Surabaya, hasdyani.putra@gmail.com \\ 2,3 Universitas Airlangga, Surabaya, tika.widiastuti@feb.unair.ac.id
}

\begin{abstract}
Abstrak: Indonesia merupakan negara yang dikenal sebagai Muslim Country Population. Namun, jumlah masyarakat Indonesia yang sudah mengenal dan mengerti mengenai wakaf masih sangat sedikit. Wakaf dapat digunakan sebagai salah satu instrumen dalam meningkatkan kehidupan sosial, ekonomi, kesejahteraan dan pendidikan masyarakat Indonesia. Namun dalam pengelolaan dan pengembangannya belum secara maksimal. Permasalahan wakaf di Indonesia adalah masih hanya sebatas potensi wakaf dan belum sepenuhnya menunjukkan kemanfaatannya. Belum adanya penilaian kinerja lembaga wakaf secara nyata oleh wakif menjadi landasan dasar dari penelitian ini. Tujuan penelitian ini untuk mengetahui faktor-faktor yang memengaruhi kepuasan wakif terhadap pelayanan lembaga wakaf. Penelitian ini menggunakan metode penelitian kuantitatif jenis explanatory research, dengan jumlah responden sebanyak 115 responden. Teknik pengolahan data yang digunakan adalah analisis regresi linear berganda. Hasil dari penelitian ini adalah kualitas program, kualitas pelayanan, kemudahan yang diberikan dan faktor emosional wakif berpengaruh signifikan secara simultan terhadap kepuasan yang diterima wakif, sedangkan hasil uji signifikansi individu diperoleh kualitas program, kualitas pelayanan, kemudahan yang diberikan dan faktor emosional berpengaruh signifikan terhadap kepuasan yang diterima wakif. Faktor-faktor inilah yang dapat digunakan sebagai landasan dalam penilaian kinerja lembaga wakaf.
\end{abstract}

Kata Kunci : wakaf, kepuasan, wakif

\begin{abstract}
Indonesia is a country known as the Muslim Country Population. However, the number of Indonesians who already know and understand about waqf is still very small. Waqf can be used as an instrument in improving the social, economic, welfare and education of the Indonesian people. However, the management and development have not been maximized. The problem of waqf in Indonesia is that it is only limited to the potential of waqf and has not fully demonstrated its benefits. The absence of a real performance appraisal of the waqf institution by wakif is the basic foundation of this research. The purpose of this study is to determine the factors that influence the satisfaction of waqf with the services of waqf institutions. This study uses quantitative research methods explanatory research, with a total of 115 respondents. The data processing technique used is multiple linear regression analysis. The results of this study are program quality, service quality, convenience provided and wakif emotional factors have a significant effect simultaneously on the satisfaction received by Wakif, while the results of individual significance test obtained program quality, service quality, convenience
\end{abstract}


provided and emotional factors have a significant effect on satisfaction. wakif received. These factors can be used as a basis in assessing the performance of waqf institutions.

Keywords: Waqf, Satisfaction, Wakif

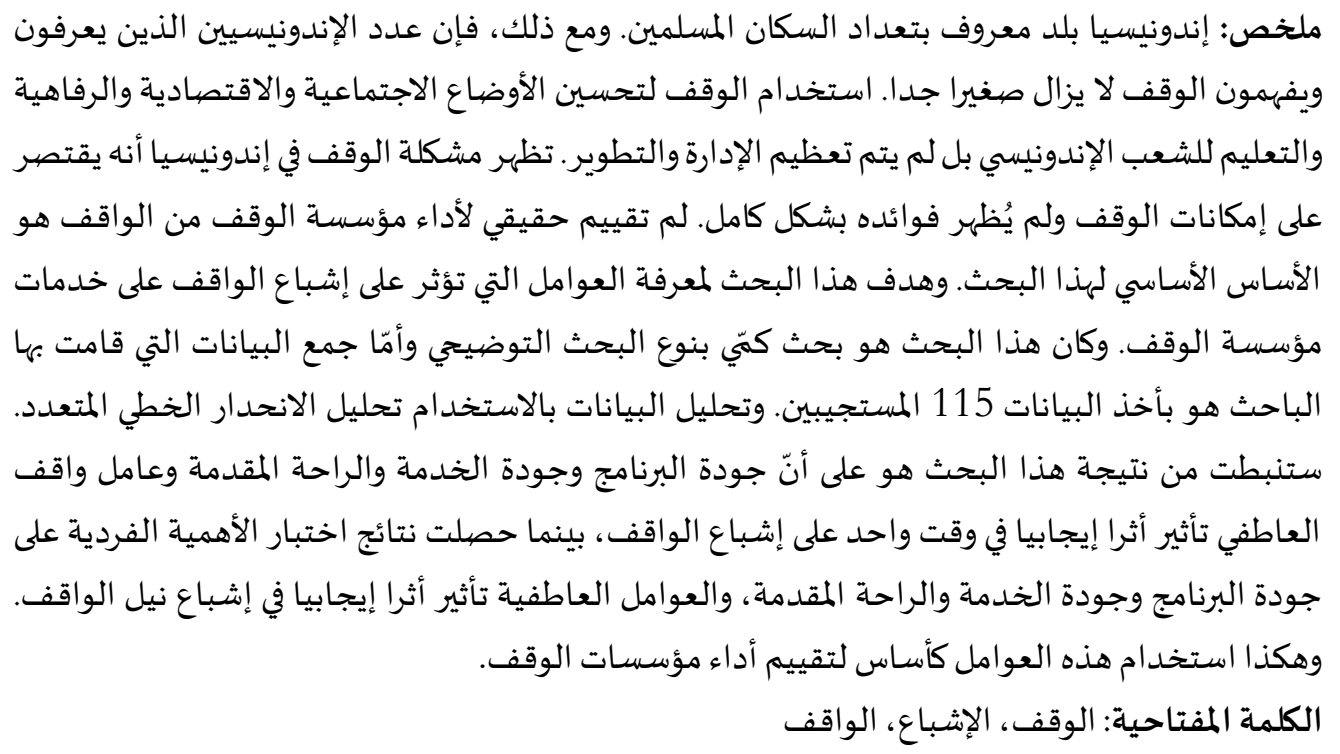

\section{PENDAHULUAN}

Islam sangat memperhatikan kondisi sosial dan ekonomi umatnya, sehingga telah dijelaskan di dalam Al-Qur'an mengenai wakaf yang dapat membantu kondisi umat dalam segi sosial dan ekonomi. Lembaga-lembaga ekonomi yang ditawarkan oleh Islam merupakan upaya strategis dalam rangka mengatasi berbagai problematika kehidupan masyarakat (Depag RI, 2004). Sebagai salah satu potensi yang mempunyai pranata keagamaan yang bersifat ekonomis, wakaf seharusnya dikelola dan dikembangkan agar menjadi suatu instrument yang mampu memberikan jawaban riil di tengah problematika kehidupan masyarakat khususnya di bidang ekonomi.

Wakaf di Indonesia sendiri kurang mengarah ke pemberdayaan ekonomi umat dan cenderung hanya untuk kegiatan-kegiatan ibadah khusus disebabkan oleh keterbatasan umat Islam dalam memahami wakaf, baik mengenai harta yang diwakafkan, peruntukan wakaf maupun nazhir wakaf (Depag RI, 2004). Hal yang penting dalam wakaf adalah berkaitan dengan kenazhiran karena berkaitan dengan pemeliharaan, produktifitas dan penyaluran hasil wakaf.

Permasalahan wakaf di Indonesia adalah belum tertata, masih hanya sebatas potensi wakaf dan belum sepenuhnya menunjukkan kemanfaatannya. Potensi besar yang belum terkumpul secara maksimal inilah dikaitkan dengan kurangnya kesadaran dan pemahaman masyarakat mengenai wakaf (Veithzal Rivai Zainal, 2016). Sehingga dibutuhkan penelitian mengenai factor-faktor yang mempengaruhi terhadap kesadaran dan pemahaman masyarakat mengenai wakaf. Dalam perkembangannya saat ini, banyak lembaga wakaf yang kesulitan menilai kinerjanya secara komprehensif, yang tidak hanya terdiri dari indikator ekonomi tetapi juga metode kualitatif yang mencakup aspek layanan wakaf yang lebih luas seperti pertumbuhan, efektivitas, transparansi, dan keberlanjutan (Nazrul Hazizi Noordin, 2017). Menurut data Departemen Agama Republik 
Indonesia terakhir terdapat 220.744 lokasi tanah wakaf dengan 52.239,94 Ha dan yang bersertifikat hanya $60,55 \%$ antara lain yaitu masjid $44,18 \%$, musholla $28,44 \%$, sekolah $10,68 \%$, pesantren, 3,57\%, makam 4,44\% dan social lainnya 8,69\%. Sedangkan wakaf produktif adalah harta benda atau pokok tetapnya wakaf tidak secara langsung digunakan untuk mencapai tujuan, tapi dikembangkan terlebih dahulu untuk menghasilkan sesuatu yang produktif dan hasilnya disalurkan sesuai dengan tujuan wakaf (Siwak Kemenag, 2020).

Faktanya, meskipun permintaan jasa wakaf melimpah, kegagalan untuk secara efektif menangkap dan menilai kinerja lembaga wakaf mungkin dapat menyebabkan penurunan aliran dana (I.A.Khalil, 2014). Hal ini memicu kebutuhan mendesak untuk membangun sistem pengukuran kinerja yang komprehensif bagi lembaga wakaf agar dapat secara efektif mengukur dan memantau kontribusi langsungnya kepada masyarakat. Faktor terpenting yang dapat mempengaruhi minat masyarakat dalam berwakaf adalah pelayanan yang diberikan. Kualitas pelayanan memiliki dampak terhadap kepuasan pelanggan, dikarenakan kualitas pelayanan yang diberikan oleh pengelola dapat menggambarkan kredibilitas, efisiensi pengelolaan, sehingga memberikan kesan langsung kepada semua institusi lainnya (kadir, 2015). Kepuasan pelanggan sendiri merupakan kunci dari suatu organisasi terutama organisasi di bidang jasa (Mohd Mokhtar, Saad, Md Salleh, Shaari, \& Mohd Nafil, 2020). Hal inilah yang menjadi landasan peneliti dalam melakukan penelitian mengenai factor-faktor yang mempengaruhi masyarakat berwakaf dari sisi kepuasan orang yang mewakafkan (Waqif) terhadap lembaga pengelola yaitu (Nazhir) di Indonesia.

\section{STUDI LITERATUR}

\section{Konsep dan pelayanan lembaga wakaf}

Pengertian wakaf dalam Kamus Besar Bahasa Indonesia adalah pemberian yang ikhlas dari seseorang berupa benda bergerak ataupun tidak bergerak bagi kepentingan umum yang dibentuk dan berkaitan dengan agama (Tim Prima Pena dalam Modul Ekonomi dan Keuangan Syariah, 2016). Wakaf menurut substansi dalam ekonomi terbagi atas wakaf langsung, merupakan pemberian pelayanan secara langsung kepada orang-orang yang berhak, seperti masjid, sekolah dan rumah sakit (Lahsasna, 2016). Wakaf produktif yang merupakan wakaf harta yang dikembangkan sehingga menghasilkan keuntungan bersih yang nantinya akan diberikan kepada orang yang berhak. Wakaf tunai yaitu wakaf yang berupa uang, yang diwakafkan untuk menjadi dana pinjaman tanpa bunga atau modal bagi usaha-usaha produktif (Uha dalam Modul Ekonomi dan Keuangan Syariah, 2016).

Sistem wakaf dalam sejarahnya telah memainkan peran penting dalam perkembangan ekonomi pra-modern dunia Muslim, terutama sistem layanan publik, mungkin juga berperan dalam menjadikan wilayah tersebut sebagai bagian yang terbelakang. Banyak klaim telah dibuat bahwa karena diwajibkan oleh hukum Islam untuk mutawalli, atau penyelenggara wakaf, untuk secara ketat mengikuti ketentuan yang ditetapkan oleh penciptanya (Shaikh, 2018). Lembaga wakaf telah berperan besar dalam menyediakan barang-barang sosial seperti pendidikan dan kesehatan, membantu orang miskin, anak yatim dan dhuafa, membangun usaha komersial dan infrastruktur untuk pelayanan keagamaan tanpa membebankan biaya apapun kepada pemerintah (Mohsin, 2008). 
Dalam penyusunan konsep dan pelayanan lembaga wakaf, (Norizan Hassan, 2018) menjelaskan dalam penelitian yang dilakukan bahwa perlunya dilakukan pembuatan kerangka yang kuat dalam pengelolaan terhadap lembaga wakaf dikarenakan komponen-komponen manajemen seperti sumber daya manusia; marketing; adminstrasi informasi dan keuangan tetap penting dalam pengelolaan lembaga wakaf yang efektif. Argumen tersebut yang memprakarsai perlunya dilakukan penelitian lebih lanjut mengenai kinerja lembaga wakaf di Indonesia. Begitu pula penelitian yang dilakukan oleh (Nazrul Hazizi Noordin, Developing a comprehensive performance measurement system for waqf institutions, 2017) memperkuat urgensi tentang hal ini dikarenakan bahwa pengelola lembaga wakaf saat ini perlu mengandalkan pelaporan keuangan dan indikator ekonomi untuk mendalami kualitas pelayanan, memperlihatkan profesionalitas lembaga tersebut dan apakah dampak lembaga tersebut berpengaruh signifikan terhadap masyarakat.

Selanjutnya dalam pelayanannya, lembaga wakaf perlu mengatasi performa pelayanan yang ada, dikarenakan (Roshayani Arshad, 2018) dalam penelitiannya menjelaskan bahwa diperlukan unsur maqasid wakaf dalam pelaksanaan kegiatannya dan pemanfaatannya yang berasal dari maqashid syariah. Setelah mengetahui perlunya performa pelayanan, lembaga wakaf juga perlu mengetahui pentingnya pengelolaan aset dalam lembaga wakaf. Menurut (Zakari, 2015) dalam penelitiannya bahwa lembaga wakaf saat ini perlu memiliki pakar dalam pengelolaan aset dan revitalisasi aset wakaf lembaga demi terciptanya pemanfaatan yang maksimal agar tidak terjadinya praktik penyimpangan.

\section{Pengelolaan Wakaf oleh Lembaga Wakaf (Nazhir)}

Lembaga-lembaga ekonomi yang ditawarkan oleh Islam merupakan upaya strategis dalam rangka mengatasi berbagai problematika kehidupan masyarakat. Sebagai salah satu potensi yang mempunyai pranata keagamaan yang ekonomis, wakaf seharusnya dikelola dan dikembangkan agar menjadi suatu instrumen yang mampu memberikan jawaban riil di tengah problematika masyarakat, khususnya di bidang ekonomi (Asy'ari, 2016).

Wakaf yang berkembang di Indonesia idealnya seperti instrumen ekonomi lain (zakat infaq dan sedekah). Namun di Indonesia, wakaf sepenuhnya belum mampu menunjukkan dan memberikan kemanfaatannya (Rivai, 2016). Lembaga independen yang bertanggung jawab mengembangkan perwakafan di Indonesia atau sering disebut Badan Wakaf Indonesia (BWI) sudah mulai menjalankan fungsinya. Salah satu contohnya adalah melakukan pembekalan kepada para nazhir di Indonesia dengan pengetahuan terkait wakaf. Pengelolaan suatu perwakafan tidak bisa dipisahkan dari para nazhir. Hal ini disebabkan karena berkembang atau tidaknya harta wakaf sangat tergantung pada nazhir. Walaupun para mujtahid tidak menjadikan nazhir sebagai salah satu rukun wakaf, namun para ulama sepakat bahwa harus menunjuk nazhir wakaf, di Indonesia nazhir ditetapkan sebagai dasar pokok perwakafan (Asy'ari, 2016).

Kata nazhir bemakna penjaga, pimpinan, pengelola, kepala, atau direktur, disebut juga dengan mutawalli, yang diberi kuasa dan persetujuan, pelaksanaan, pimpinan, atau arahan (Lubis, Suhrawadi dan Wajdi, 2016). Nazhir sebagai pengelola utama wakaf memiliki tanggung jawab yang besar, mulai dari mendatakan wakaf ke BWI, mengelola wakaf hingga menghasilkan dan mengalokasikan manfaatnya serta mempublikasikan perkembangan wakaf (Rivai, 2016). Nazhir dapat berupa perseorangan ataupun suatu perusahaan atau organisasi. Nazhir perseorangan harus memenuhi beberapa persyaratan yaitu warga negara Indonesia, dewasa, amanah, mampu 
secara jasmani dan rohani serta tidak terhalang perbuatan hukum. Persyaratan yang sama untuk organisasi dan perusahaan korporasi dengan tambahan bahwa organisasi atau perusahaan korporasi bergerak dalam bidang sosial, pendidikan, kemasyarakatan dan/atau keagamaan Islam. (Lubis, Suhrawadi dan Wajdi, 2016). Undang-undang wakaf pasal 11 menjelaskan mengenai tugas-tugas nazhir. Pelaksanaan tugasnya sebagai nazhir wakaf, nazhir menerima imbalan yang besarnya tidak lebih dari $10 \%$ hasil bersih investasi yang telah dilakukan, hal ini sesuai dengan ketentuan pasal 12 Undang-undang wakaf (UU RI Nomor 4 Tahun 2004 tentang Wakaf). Namun masih bisa ditemukan masalah bagi para nazhir jika belum berpengalaman dalam pemberdayaan harta benda wakaf sehingga dapat menghasilkan dan memberikan nilai ekonomi sebagai ciri khas wakaf (Veithzal Rivai Zainal, 2016). Hal inilah yang mengharuskan nazhir memiliki sifat profesional dan memberikan kualitas pelayanan yang baik terhadap wakif. Selanjutnya dalam (Usman, 2013) menjelaskan bahwa dalam Undang-Undang Nomor 41 Tahun 2004 telah memperluas benda yang dapat diwakafkan oleh wakif, yang secara umum terbatas kepada tidak bergerak atau benda tetap seperti tanah dan bangunan, kini benda bergerak, baik berwujud maupun tidak berwujud dan benda bergerak lainnya yang dapat diwakafkan. Dikemukakan bahwa wakif (pihak yang mewakafkan harta bendanya) dapat mewakafkan benda bergerak berupa uang (wakaf uang), yang dilakukan melalui Lembaga Keuangan Syariah yang ditunjuk oleh menteri yang bertanggung jawab di bidang agama sebagai Lembaga Keuangan Syariah Penerima Wakaf Uang (LKS-PWU).

\section{Kepuasan Pelanggan terhadap Lembaga Wakaf}

Kepuasan Pelanggan merupakan kunci sukses sebuah organisasi termasuk organisasi yang berbasis pelayanan (Mohd Mokhtar et al., 2020). Menurut (Mujaini, 2012) kepuasan pelanggan merupakan tingkat harapan dan harapan pembeli terhadap suatu produk. Oleh karena itu, kepuasan adalah perasaan senang atau sedih yang timbul dari perbandingan antara persepsi dan harapan pelanggan. Kepuasan dapat dianggap sebagai penilaian konsumen terhadap perbandingan antara harapan pelanggan dan layanan nyata yang diberikan oleh suatu organisasi. Namun dalam lembaga wakaf, kepuasan wakif adalah ketika wakif mendapatkan kualitas pelayanan yang baik dalam proses pemberian wakafnya di lembaga wakaf. Menurut Oliver (Oliver, 1980) secara umum kepuasan dapat dianggap sebagai penilaian konsumen terhadap perbandingan antara ekspektasi pelanggan dengan layanan nyata yang diberikan oleh suatu organisasi. Namun dalam lembaga wakaf, kepuasan wakif adalah ketika wakif mendapatkan kualitas pelayanan yang baik saat mengurus proses pemberian wakafnya di lembaga wakaf. Berbagai penelitian telah dilakukan tentang pemanfaatan lembaga wakaf dan penerimaan para wakif terhadap layanan yang diterima. Hal ini perlu dicermati karena dapat berdampak buruk terhadap kualitas layanan yang selama ini dipraktikkan di lembaga wakaf di Indonesia. Namun demikian, faktor kualitas pelayanan perlu dipertimbangkan kembali untuk memastikan pengaruhnya terhadap kepuasan wakif di lembaga wakaf.

Persaingan dalam memperebutkan pelanggan membutuhkan usaha yang keras, maka diperlukan strategi kepuasan pelanggan dimana dalam penelitian ini yang dimaksud adalah wakif. Strategi yang dapat meningkatkan kepuasan pelanggan menurut (Tjiptono dalam Huda, 2013) adalah Strategi Relationship Marketing, Strategi Superior Customer Service, Strategi Unconditional Guarantees, Strategi Penanganan Keluhan yang Efisien, Strategi Peningkatan Kinerja Perusahaan, Strategi Penerapan Quality Function Development (QFD). Pengukuran 
tingkat kepuasaan pelanggan, terutama pada perusahaan jasa adalah dengan membandingkan antara keinginan dengan kenyataan yang diterima oleh konsumen sendiri (Tjiptono dalam Huda, 2013). Kualitas layanan sangat erat kaitannya dengan kepuasan pelanggan.

Menurut Kamil dan Ahmad dalam (Hafizah Zainal, 2016), ketidakpercayaan terhadap suatu lembaga terutama dalam hal transparansi dan inefisiensi dalam pengelolaan penyaluran dana menyebabkan ketidakpatuhan. Semakin tinggi kepuasan terhadap lembaga maka semakin tinggi pula kepatuhan donasinya. Sejalan dengan argumen di atas, diharapkan pemangku kepentingan yang memiliki tingkat kepuasan yang tinggi atas penyaluran dana wakaf akan memberikan kontribusi kepercayaan yang lebih besar kepada lembaga wakaf dan begitu pula sebaliknya.

\section{Kualitas Pelayanan pada Lembaga Wakaf}

Kualitas layanan dapat didefinisikan sebagai perbedaan antara ekspektasi yang dirasakan dan ekspektasi aktual, atau evaluasi keseluruhan dari keuntungan dan pentingnya produk atau jasa atau sikap. Pengukuran kualitas layanan paling awal telah diperkenalkan oleh Parasuraman et.al. dimana kualitas layanan diukur dengan SERVQUAL yang memiliki lima dimensi; keandalan, daya tanggap, jaminan, empati (Elmas, Rahajeng, \& Herminto, 2016; Jalil \& Mohd Ramli, 2014; Mohd Mokhtar et al., 2020). Faktor yang mempengaruhi kepuasaan pelanggan terdiri dari kualitas produk yang dimiliki produsen, harga yang ditetapkan, kualitas pelayanan yang diberikan produsen, faktor emosional dari konsumen, dan kemudahan yang diterima oleh konsumen. Namun karena wakaf bergerak di bidang jasa, faktor yang terpenting adalah kualitas pelayanan, faktor emosional konsumen, kemudahan yang diterima oleh konsumen (wakif).

Kualitas pelayanan sendiri menjadi salah saktu faktor yang mempengaruhi kepuasan pelanggan khususnya dalam bidang lembaga (Sany Sanuri Mohd Mokhtar, 2020) yang nota benenya adalah kualitas pelayanan memberi dampak terhadap kepuasan para donatur (wakif) dalam berwakaf. Kualitas pelayanan juga menjadi poin penting dalam mengetahui kinerja sebuah lembaga wakaf seperti penelitian yang dilakukan oleh (Zain, 2017) yang menemukan bahwa kualitas pelayanan adalah salah satu faktor yang dapat menggambarkan keberhasilan organisasi wakaf.

Menurut penelitian (A.L.F Saad, 2009) dan (Hafizah Zainal, 2016), peran lembaga dalam memberikan kualitas pelayanan kepada masyarakat merupakan faktor penting untuk menarik dan mendorong pengusaha membayar zakat. Mereka juga menyatakan bahwa kualitas layanan dipertimbangkan dengan baik ketika organisasi memenuhi harapan pelanggan sebelum dan sesudah layanan. Selain itu, (A.L.F Saad, 2009) menunjukkan bukti empiris bahwa dengan meningkatkan kualitas layanan maka kepatuhan terhadap zakat akan semakin baik. Sejalan dengan pembahasan di atas, diasumsikan bahwa kualitas layanan lembaga wakaf akan menentukan kepercayaan stakeholders terhadap lembaga wakaf.

\section{HIPOTESIS}

Berdasarkan berbagai teori dan konsep penelitian yang digunakan, maka hipotesis yang dirumuskan untuk tujuan penelitian mengetahui faktor-faktor yang mempengaruhi kepuasan wakif terhadap pelayanan lembaga wakaf adalah "diduga kualitas program, kualitas pelayanan, kemudahan yang diberikan serta faktor emosional secara signifikan berpengaruh terhadap kepuasan wakif pada pelayanan lembaga wakaf'. 


\section{METODE PENELITIAN}

Dalam penelitian ini, peneliti menggunakan metode kuantitatif. Jenis pendekatan yang peneliti gunakan adalah jenis pendekatan analisis deskripsi kuantitatif dengan penelitian explanatory research. Penelitian explanatory research merupakan penelitian yang menjelaskan hubungan antara variabel X dan variabel Y. Penelitian ini menggunakan data primer berupa kuesioner hasil dari pengisian oleh masyarakat yang telah melakukan wakaf. Peneliti juga menggunakan studi literatur terdahulu dari buku dan jurnal.

Data didapatkan dari kuesioner yang disebar ke seluruh masyarakat di daerah Surabaya yang pernah melakukan wakaf, dengan teknik sampling acak. Kuesioner yang digunakan dalam bentuk google form sehingga mudah diakses, namun tidak mengurangi keabsahan keuesioner untuk dapat diakses responden sesuai dengan kriteria yang telah ditetapkan peneliti. Kuesioner terdiri dari 4 variabel independen yaitu Kualitas program, Kualitas pelayanan, Kemudahan yang diberikan, dan Faktor emosional serta 1 variabel dependen yaitu kepuasan wakif terhadap lembaga wakaf, tiap-tiap variabel terdiri dari 5 poin kuesioner. Sebelum kuesioner disebarkan kepada responden, kuesioner diuji validitas dan rebilitas terlebih dahulu. Uji validitas menurut Sugiyono (dalam Kurniawati, 2016), instrumen dikatakan valid berarti menunjukkan alat ukur yang dipergunakan untuk mendapatkan data tersebut valid atau dapat digunakan untuk mengukur yang seharusnya diukur. Uji reliabilitas menurut Sugiyono dalam (Kurniawati, 2016) menjelaskan bahwa berguna untuk menetapkan apakah kuesioner dapat digunakan lebih dari satu kali, paling tidak oleh responden yang sama dan akan menghasilkan data yang konsisten.

Populasi data yang digunakan dalam penelitian ini adalah semua orang sebagai donatur wakaf (wakif) yang berada di Surabaya. Sehingga didapatkan sampel penelitian sebanyak 115 responden selama periode bulan September 2020. Pengolahan data dengan beberapa uji (metode) untuk mendapatkan hasil yang diharapkan. Pengolahan data ini menggunakan bantuan program SPSS 22.

Teknik pengolahan data menggunakan analisis regresi linier berganda. Fungsi analisis regresi linier berganda yaitu untuk mengukur kekuatan antara dua variabel atau lebih, selanjutnya dapat juga digunakan untuk menunjukkan arah hubungan antara variabel dependen dengan variabel independen (Ghozali dalam Kurniawati, 2016). Penggunaan analisis regresi berganda bertujuan untuk membuat model matematis dari pengaruh kualitas program, kualitas pelayanan, kemudahan yang diberikan, dan faktor emosional terhadap faktor- faktor yang mempengaruhi kepuasan donatur (Wakif). Dari model tersebut dapat diketahui berapa besarnya pengaruh kualitas program, kualitas pelayanan, kemudahan yang diberikan, dan faktor emosional terhadap faktor- faktor yang mempengaruhi kepuasan donatur (Wakif).

$$
\begin{array}{ll}
Y i=b o+b 1 \times 1+b 2 \times 2+b 3 \times 3+b 4 \times 4+\epsilon \\
\text { Keterangan : } & \\
\text { X1 } & =\text { Kualitas Program } \\
\text { X2 } & =\text { Kualitas Pelayanan } \\
\text { X3 } & =\text { Kemudahan yang Diberikan }
\end{array}
$$




$$
\begin{array}{ll}
\mathrm{X} 4 & =\text { Faktor Emosional } \\
\mathrm{Y} & =\text { Kepuasan Donatur (Wakif) } \\
\mathrm{b} 0-\mathrm{b} 4 & =\text { Koefisien Regresi } \\
\mathrm{E} & =\text { Kesalahan Acak }
\end{array}
$$

\section{HASIL DAN PEMBAHASAN}

Hasil dari penelitian ini didapatkan bahwa item kuesioner yang telah dilakukan uji realibilitas dan validitas karena nilai sig.r item pertanyaan ini lebih kecil dari $0.05(\alpha=0.05)$ yang berarti tiap-tiap item variabel adalah valid, sehingga item-item tersebut dapat digunakan untuk mengukur variabel penelitian. Uji reliabilitas disimpulkan bahwa nilai dari tiap item variabel lebih dari 0,6. Sehingga item kuesioner untuk penelitian ini realibel.

Distribusi data demografi dalam penelitian menunjukkan bahwa $64 \%$ responden merupakan laki-laki dan $36 \%$ wanita. Sedangkan untuk persebaran umur, responden terbanyak dari kalangan usia 20 hingga 29 tahun sebesar 69,5\%. Distribusi latar belakang pekerjaan responden paling banyak pada lain-lain sebesar $47 \%$, kemudian pegawai swasta sebanyak $39 \%$. Data distribusi demografi dapat dilihat pada tabel 1.

Tabel 1. Distribusi data demografi

\begin{tabular}{|l|l|}
\hline Parameter & $\begin{array}{l}\text { Total (\%) } \\
\mathbf{N}=\mathbf{1 1 5}\end{array}$ \\
\hline $\begin{array}{l}\text { Jenis Kelamin } \\
\text { Laki - laki } \\
\text { Perempuan }\end{array}$ & $64 \%$ \\
& $36 \%$ \\
\hline Usia & \\
$<20$ tahun & $5,2 \%$ \\
$20-29$ tahun & $69,5 \%$ \\
$30-39$ tahun & $14 \%$ \\
$40-49$ tahun & $6 \%$ \\
$>50$ tahun & $5,3 \%$ \\
\hline Pekerjaan & \\
PNS & $12,3 \%$ \\
Pegawai Swasta & $29,5 \%$ \\
Pengusaha & $10,4 \%$ \\
Pedagang & $0,8 \%$ \\
Lain - lain & $47 \%$ \\
\hline
\end{tabular}

\section{Koefisien Determinasi}

Faktor pertama yang dilihat dari pengujian hipotesis kali ini adalah adjusted $\mathrm{R}$ square atau yang biasa disebut dengan koefisien determinasi. Dalam interpretasinya, nilai adjusted $\mathrm{R}$ square dapat naik ataupun turun dengan adanya penambahn variabel baru, tergantung dari korelasi antara variabel independen tambahan tersebut dengan variabel dependen. Hasil koefisien determinasi dalam penelitian kali ini akan dijelaskan dalam tabel 2 berikut ini : 
Tabel 2. Nilai adjusted $R$ square

Model Summary

\begin{tabular}{|l|l|r|r|r|}
\hline Model & R & R Square & \multicolumn{1}{|c|}{$\begin{array}{c}\text { Adjusted R } \\
\text { Square }\end{array}$} & $\begin{array}{c}\text { Std. Error of } \\
\text { the Estimate }\end{array}$ \\
\hline 1 &, $709^{\mathrm{a}}$ &, 503 &, 584 &, 357 \\
\hline
\end{tabular}

a. Predictors: (Constant), $\mathrm{X}_{4}, \mathrm{X}_{1}, \mathrm{X}_{3}, \mathrm{X}_{2}$

Besarnya nilai koefesien determinasi pada model regresi linier berganda ditunjukkan oleh nilai adjusted $R$ square. Nilai adjusted $R$ square sebesar 0,584 dapat diinterpretasikan seperti nilai $R$ Square pada regresi berganda. Uji regresi linear berganda diperoleh nilai adjusted $R$ square sebesar 0,584 yang berarti variabilitas variabel dependen yang dapat dijelaskan oleh variabel independen adalah sebesar 58,4\%, sedangkan sisanya sebesar 41,6\% dijelaskan oleh variabel lain di luar model penelitian. Hal ini menunjukkan bahwa variabel kualitas program, kualitas pelayanan, kemudahan yang diberikan dan faktor emosional wakif memberikan pengaruh terhadap persepsi Naz̧hir mengenai wakaf uang. Berdasarkan uji regresi logistik linear didapatkan hasil seperti yang tertera pada tabel 3.

Tabel 3. Hasil uji hipotesis

ANOVA $^{\text {a }}$

\begin{tabular}{|ll|r|r|r|r|r|}
\hline Model & & \multicolumn{1}{c|}{$\begin{array}{c}\text { Sum of } \\
\text { Squares }\end{array}$} & \multicolumn{1}{c|}{ df } & Mean Square & F & Sig. \\
\hline 1 & Regression & 14,131 & 4 & 3,533 & 27,778 &, $000^{\mathrm{b}}$ \\
& Residual & 13,990 & 110 &, 127 & & \\
& Total & 28,122 & 114 & & & \\
\hline
\end{tabular}

a. Dependent Variable: $Y$

b. Predictors: (Constant), X4, X1, X3, X2

Tabel 4. Uji regresi linear berganda

\section{Coefficients $^{\mathrm{a}}$}

\begin{tabular}{|c|c|c|c|c|c|c|}
\hline \multirow[b]{2}{*}{ Mod } & & \multicolumn{2}{|c|}{ Unstandardized Coefficients } & \multirow{2}{*}{$\begin{array}{c}\begin{array}{c}\text { Standardized } \\
\text { Coefficients }\end{array} \\
\text { Beta }\end{array}$} & \multirow[b]{2}{*}{$\mathrm{t}$} & \multirow[b]{2}{*}{ Sig. } \\
\hline & & $B$ & Std. Error & & & \\
\hline \multirow[t]{5}{*}{1} & (Constant) &, 325 &, 303 & & 1,072 &, 286 \\
\hline & KUALITAS_PELAYANAN &, 046 &, 102 &, 047 &, 454 & 651 \\
\hline & KUALITAS_PROGRAM &, 142 &, 090 & 143 & 1,575 & .118 \\
\hline & $\begin{array}{l}\text { KEMUDAHAN_YANG_DIB } \\
\text { ERIKAN }\end{array}$ & 290 &, 092 & 293 & 3,157 &, 002 \\
\hline & FAKTOR_EMOSIONAL & , 392 &, 084 &, 382 & 4,652 &, 000 \\
\hline
\end{tabular}

a. Dependent Variable: KEPUASAN_WAKIF 
Hasil persamaan regresi berganda diatas menunjukkan hubungan antara variabel independen yakni kualitas program, kuallitas pelayanan, kemudahan yang diberikan, dan faktor emosional dengan variabel dependennya yaitu kepuasan wakif. Menurut Gujarati (2003), model ekonometrika yang baik adalah model ekonometrika yang harus memenuhi syarat pengujian asumsi dan termasuk kedalam kriteria statistika lainnya dalam ekonometrika.

\section{Pengaruh kualitas program terhadap Kepuasan Wakif terhadap Pelayanan Lembaga}

\section{Wakaf (Nazhir)}

Tabel 5. Pengaruh kualitas program terhadap kepuasan wakif

Coefficients $^{a}$

\begin{tabular}{|c|c|c|c|c|c|c|}
\hline \multirow[b]{2}{*}{ Model } & & \multicolumn{2}{|c|}{ Unstandardized Coefficients } & \multirow{2}{*}{$\begin{array}{c}\begin{array}{c}\text { Standardized } \\
\text { Coefficients }\end{array} \\
\text { Beta } \\
\end{array}$} & \multirow[b]{2}{*}{$\mathrm{t}$} & \multirow[b]{2}{*}{ Sig. } \\
\hline & & B & Std. Error & & & \\
\hline \multirow[t]{2}{*}{1} & (Constant) & 1,748 &, 298 & & 5,869 &, 000 \\
\hline & KUALITAS_PROGRAM & , 471 &, 083 & 472 & 5,690 &, 000 \\
\hline
\end{tabular}

a. Dependent Variable: KEPUASAN_WAKIF

Hasil penelitian menunjukkan bahwa variabel kualitas pelayanan (X1) berpengaruh secara signifikan terhadap kepuasan donatur $(\mathrm{Y})$, hal ini dapat dilihat dari hasil penelitian yang menghasilkan t hitung sebesar 6,428 dengan nilai signifikansi $0,000(\alpha \leq 0,05)$. Pada model ekonometrika di atas menunjukkan ketika kualitas pelayanan (X1) naik maka akan meningkatkan kepuasan donatur terhadap kinerja lembaga wakaf (Naz̧bir). Setiap kenaikan sebesar satu persatuan pada setiap variabel independennya maka akan mempengaruhi Kepuasan donatur dan terjadi kenaikan sebesar 0,046 pada variabel kualitas pelayanan (X1).

Hasil ini menunjukkan bahwa donatur mempertimbangkan variabel kualitas pelayanan untuk melakukan keputusan mereka dalam menentukan kepuasan yang mereka dapat dari pelayanan lembaga wakaf ( $\mathrm{Nazhir).} \mathrm{Hasil} \mathrm{penelitian} \mathrm{ini} \mathrm{sejalan} \mathrm{dengan} \mathrm{penelitian} \mathrm{yang} \mathrm{dilakukan} \mathrm{(Rifai,}$ Adam, dan Ponirin, 2016), hasil penelitiannya menunjukkan bahwa adanya pengaruh signifikan antara kualitas pelayanan yang terdiri dari bukti fisik, empati, daya tanggap, keandalan, dan jaminan terhadap nilai pelanggan. Jumlah sumber daya yang memadai, fasilitas fisik yang baik, daya tanggap dan keandalan seorang Naz̧bir dapat berpengaruh terhadap kepuasan wakif.

\section{Pengaruh Kualitas Pelayanan Terhadap Kepuasan Wakif terhadap Pelayanan Lembaga Wakaf (Nazhir)}

Tabel 6. Pengaruh kualitas pelayanan terhadap kepuasan wakif

Coefficients $^{\mathrm{a}}$

\begin{tabular}{|c|c|c|c|c|c|c|}
\hline \multirow{2}{*}{\multicolumn{2}{|c|}{ Model }} & \multicolumn{2}{|c|}{ Unstandardized Coefficients } & \multirow{2}{*}{$\begin{array}{c}\begin{array}{c}\text { Standardized } \\
\text { Coefficients }\end{array} \\
\text { Beta }\end{array}$} & \multirow[b]{2}{*}{$t$} & \multirow[b]{2}{*}{ Sig. } \\
\hline & & $B$ & Std. Error & & & \\
\hline \multirow[t]{2}{*}{1} & (Constant) & 1,637 & 281 & & 5,823 &, 000 \\
\hline & KUALITAS_PELAYANAN & .512 &, 080 & .517 & 6,428 &, 000 \\
\hline
\end{tabular}

a. Dependent Variable: KEPUASAN_WAKIF 
Hasil penelitian menunjukkan bahwa variabel kualitas pelayanan (X2) berpengaruh secara signifikan terhadap kepuasan donatur $(\mathrm{Y})$, hal ini dapat dilihat dari hasil penelitian yang menghasilkan t hitung sebesar 6,428 dengan nilai signifikansi $0,000 \quad(\alpha \leq 0,05)$. Hasil ini menunjukkan bahwa donatur mempertimbangkan variabel kualitas pelayanan untuk melakukan keputusan mereka dalam menentukan kepuasan yang mereka dapat dari pelayanan lembaga wakaf (Nazhir). Hasil penelitian ini sejalan dengan penelitian yang dilakukan (Rifai, Adam, dan Ponirin, 2016), hasil penelitiannya menunjukkan bahwa adanya pengaruh signifikan antara kualitas pelayanan yang terdiri dari bukti fisik, empati, daya tanggap, keandalan, dan jaminan terhadap nilai pelanggan. Jumlah sumber daya yang memadai, fasilitas fisik yang baik, daya tanggap dan keandalan seorang nazhir dapat berpengaruh terhadap kepuasan wakif.

4. Pengaruh Kemudahan yang Diberikan Terhadap Kepuasan Wakif terhadap Pelayanan Lembaga Wakaf (Nazhir)

Tabel 7. Pengaruh kemudahan yang diberikan terhadap kepuasan wakif

Coefficients $^{a}$

\begin{tabular}{|c|c|c|c|c|c|c|}
\hline \multirow[b]{2}{*}{ Model } & & \multicolumn{2}{|c|}{ Unstandardized Coefficients } & \multirow{2}{*}{$\begin{array}{c}\begin{array}{c}\text { Standardized } \\
\text { Coefficients }\end{array} \\
\text { Beta } \\
\end{array}$} & \multirow[b]{2}{*}{$\mathrm{t}$} & \multirow[b]{2}{*}{ Sig. } \\
\hline & & $\mathrm{B}$ & Std. Error & & & \\
\hline 1 & (Constant) & 1,368 &, 262 & & 5,227 &, 000 \\
\hline & $\begin{array}{l}\text { KEMUDAHAN_YANG_DIB } \\
\text { ERIKAN }\end{array}$ &, 593 &, 075 &, 599 & 7,945 &, 000 \\
\hline
\end{tabular}

a. Dependent Variable: KEPUASAN_WAKIF

Hasil penelitian menunjukkan bahwa variabel kemudahan yang diberikan (X3) berpengaruh secara signifikan terhadap kepuasan donatur $(Y)$ dengan t hitung sebesar 5,227 dengan nilai signifikansi $0,000(\alpha \leq 0,05)$. Hasil ini menunjukkan bahwa donatur mempertimbangkan variabel kemudahan yang diberikan untuk melakukan keputusan mereka dalam menentukan kepuasan yang mereka dapat dari pelayanan lembaga wakaf (Nazhir). Variabel kemudahan yang diberikan dalam penelitian kali ini menjadi salah satu variabel yang memiliki pengaruh besar dalam pemilihan donatur yang dapat menentukan kepuasan yang diterima oleh para donatur. Hal tersebut dikarenakan kemudahan yang dirasakan oleh para donatur membuat mereka semakin mudah untuk berdonasi dan mewakafkan hartanya. Dari lokasi yang mudah untuk ditempuh, informasi yang mudah didapatkan, prosedur yang mudah dalam berwakaf, dan teknologi yang mendukung menjadi beberapa alasan yang kuat bagi mereka dalam melakukan kegiatan wakaf pada lembaga wakaf (Nazhir) (Zainal, Abu Bakar, \& Saad, 2016).

5. Pengaruh Faktor Emosional Terhadap Kepuasan Wakif terhadap Pelayanan Lembaga Wakaf (Nazhir)

Tabel 8. Pengaruh faktor emosional terhadap kepuasan wakif 
Coefficients $^{a}$

\begin{tabular}{|c|c|c|c|c|c|c|}
\hline \multirow{2}{*}{\multicolumn{2}{|c|}{ Model }} & \multicolumn{2}{|c|}{ Unstandardized Coefficients } & \multirow{2}{*}{$\begin{array}{c}\begin{array}{c}\text { Standardized } \\
\text { Coefficients }\end{array} \\
\text { Beta } \\
\end{array}$} & \multirow[b]{2}{*}{$\mathrm{t}$} & \multirow[b]{2}{*}{ Sig. } \\
\hline & & $B$ & Std. Error & & & \\
\hline \multirow[t]{2}{*}{1} & (Constant) & 1,123 & .279 & & 4,027 &, 000 \\
\hline & FAKTOR_EMOSIONAL &, 634 & 076 & 617 & 8,335 &, 000 \\
\hline
\end{tabular}

a. Dependent Variable: KEPUASAN_WAKIF

Hasil penelitian menunjukkan bahwa variabel faktor emosional (X4) berpengaruh secara signifikan terhadap kepuasan donatur $(\mathrm{Y})$ dengan thitung sebesar 4,027 dengan nilai signifikansi $0,000(\alpha \leq 0,05)$. Hasil ini menunjukkan bahwa donatur mempertimbangkan variabel kemudahan yang diberikan untuk melakukan keputusan mereka dalam menentukan kepuasan yang mereka dapat dari pelayanan lembaga wakaf (Nazhir). Hal tersebut dapat terjadi dikarenakan para donatur yang tergabung dalam lembaga wakaf (Nazhir) Yayasan Baitur Rahmah Sejahtera memiliki kesadaran dalam melakukan kegiatan sosial dengan menyisihkan sebagian dana yang mereka miliki untuk diwakafkan kepada lembaga wakaf (Nazhir) agar kesejahteraan sosial lebih merata. Sebagian besar dari para donatur juga memiliki kesadaran tinggi terhadap pemahaman agama yang menguatkan niat mereka dalam mewakafkan sebagian hartanya di jalan Allah SW'T.

Pada tahap ini menguraikan mengenai hasil dan analisis data penelitian yang dilakukan pada bulan September 2020 terhadap masyarakat yang melakukan kegiatan wakaf. Berdasarkan analisis regresi yang telah dilakukan, mengenai pengaruh variabel kualitas program, kualitas pelayanan, kemudahan yang diberikan, dan faktor emosional terhadap kepuasan wakiflembaga wakaf (Naz̧hir) yang tersebar di Indonesia. Terdapat informasi bahwa pengaruh kualitas pelayanan (X1-X4) sebagai variabel bebas yang digunakan sebagai variabel bebas dengan kepuasan donatur $(\mathrm{Y})$ sebagai variabel terikat secara bersama-sama adalah signifikan, dan hubungan antara keduanya kuat sebesar 0,584. Variabel bebas tersebut mampu menjelaskan variabel terikat sebesar 58,4\%, sedangkan sisanya dijelaskan oleh variabel lainnya.

Hasil perhitungan menggunakan analisis regresi linier berganda pada uji t diperoleh nilai koefisien untuk masing-masing variabel independen adalah 0,046 untuk variabel kualitas program (X1), 0,142 untuk variabel kualitas pelayanan (X2), 0,290 untuk variabel kemudahan yang diberikan (X3), dan 0,392 untuk variabel faktor emosional (X4). Nilai koefisien regresi yang menunjukkan keseluruhan positif dan menjelaskan bahwa pengaruh dari masing-masing variabel bebas yang terdiri dari kualitas program (X1), variabel kualitas pelayanan (X2), kemudahan yang diberikan (X3), dan faktor emosional (X4) berpengaruh searah terhadap kepuasan wakif $(\mathrm{Y})$.

\section{KESIMPULAN}

Berdasarkan uji analisis regresi linier dan pembahasan yang telah dilakukan dapat ditarik kesimpulan bahwa kualitas program, kualitas pelayanan, kemudahan yang diberikan dan faktor emosional wakif berpengaruh signifikan secara simultan terhadap kepuasan yang diterima wakif, sedangkan hasil uji signifikansi individu diperoleh kualitas program, kualitas pelayanan, kemudahan yang diberikan dan faktor emosional berpengaruh signifikan terhadap kepuasan yang diterima wakif. Faktor-faktor inilah yang dapat digunakan sebagai landasan dalam 
penilaian kinerja lembaga wakaf. Hal ini sesuai dengan hipotesa yang dirumuskan peneliti bahwa factor-faktor tersebut sebagai indikator kepuasan pelanggan (wakif) berpengaruh terhadap kinerja lembaga wakaf.

Kualitas program memiliki hasil yang signifikan karena beberapa program yang dimiliki oleh lembaga wakaf (Nazhir) cukup bagus dalam melayani para donatur maupun pengelolaan dan pendistribusian dana wakaf sendiri. Kualitas pelayanan juga memiliki hasil yang signifikan karena donatur mempertimbangkan variabel kualitas pelayanan untuk melakukan keputusan mereka dalam menentukan kepuasan yang mereka dapat dari pelayanan lembaga wakaf (Nazhir) yang meliputi jumlah sumber daya yang memadai, fasilitas fisik yang baik, daya tanggap dan keandalan seorang nazhir dapat berpengaruh terhadap kepuasan wakif.

Kemudahan yang diberikan juga memiliki pengaruh yang signifikan dikarenakan kemudahan yang dirasakan oleh para donatur membuat mereka semakin mudah untuk berdonasi dan mewakafkan hartanya. Dari lokasi yang mudah untuk ditempuh, informasi yang mudah didapatkan, prosedur yang mudah dalam berwakaf, dan teknologi yang mendukung menjadi beberapa alasan yang kuat bagi mereka dalam melakukan kegiatan wakaf. Selanjutnya faktor emosional berpengaruh secara signifikan dikarenakan hal tersebut dapat terjadi dikarenakan para donatur memiliki kesadaran dalam melakukan kegiatan sosial dengan menyisihkan sebagian dana yang mereka miliki untuk diwakafkan kepada lembaga wakaf (Nazhir) agar kesejahteraan sosial lebih merata.

\section{REFERENSI}

A.L.F Saad, M. B. (2009). Peraturan pembayaran zakat kepada institusi zakat: Sikap peniaga dan kesannya terhadap gelagat pembayaran zakat perniagaan. Jurnal Syariah, 607-630.

Asy'ari, H. (2016). Pengelolaan dan Pengembangan Wakaf Produktif Yayasan Pondok Pesantren Miftahul Ulum Al-Yasini.

Atabik, A. (2014). Manajemen pengelolaan wakaf tunai di indonesia. Ziswaf, 1(1), 82-107.

Depag RI. (2004). Pedoman Pengelolaan dan Pengembangan Wakaf. Jakarta : Ditjen Bimas Islam dan Penyelenggara Haji Proyek Peningkatan Pemberdayaan Wakaf.

Elmas, M. S. H., Rahajeng, Y., \& Herminto, T. (2016). Kepuasan Pelanggan Sebagai Mediator Hubungan Antara Kualitas Pelayanan Dan Loyalitas Pelanggan ( Donatur) Pada Baitul Maal Hidayatullah Unit Penghimpunan Perwakilan (Bmh Upp) Probolinggo, 76-86.

Hafizah Zainal, A. A. (2016). Reputation, Satisfaction of Zakat Distribution, and Service Quality as Determinant of Stakeholder Trust in Zakat Institutions. International Journal of Economics and Financial Issues, 72-76.

I.A.Khalil, D. A. (2014). Waqf fund management in Kuwait and Egypt: Can Malaysia learn from their experiences? International Conference on Masjid, Zakat and Waqf, 69. 
Irawan, Handi. 2008. Sepuluh Prinsip Kepuasan Pelanggan. Jakarta: Elex Media Komputindo. Kurniawati, Aprilia. 2016. Pengaruh Service Scape Dan Service Excellence Terhadap Kepuasan Pelanggan (Studi Pada Pelanggan Diva Family Karaoke Malang). Malang: Universitas Brawijaya.

Jalil, A., \& Mohd Ramli, A. (2014). Conceptualisation of corporate waqf. Seminar Waqf Iqlimi 2014, 310-321. Retrieved from http://ddms.usim.edu.my:80/jspui/handle/123456789/9866

Kadir, A. a. (2015). Faktor-Faktor Yang Mempengaruhi Kepuasan Pelanggan Terhadap Kualiti Perkhidmatan Zakat: Kajian kes Pejabat Zakat Daerah Baling (PZDB), Kedah. Universiti Utara Malaysia.

Mohsin, M. (2008). 'Cash Waqf a New Financial Product Model Aspects of Shariah. Islamic Banking, Accounting and Finance Conference (iBAF 2008).

Mujaini, T. (2012). Zakat Al-mal Al-mustafad Amalan dan Pengalaman di Malaysia. Pusat Pungutan Zakat.

Nazrul Hazizi Noordin, S. N. (2017). Developing a comprehensive performance measurement system for waqf institutions. International Journal of Social Economics, 921-936.

Norizan Hassan, A. A.-R. (2018). Developing a New Framework of Waqf Management. International Journal of Academic Research in Business and Social Sciences, 287 - 305.

Oliver, R. L. (1980). A Cognitive Model of the Antecedents and Consequences of Satisfaction Decisions. J. Mark. Res, 460-469.

Roshayani Arshad, N. M. (2018). Modelling Maqasid Waqf Performance Measures in Waqf Institutions. Global Journal Al Thaqafah, 157 - 169.

Sany Sanuri Mohd Mokhtar, S. S. (2020). The Influence of Service Quality and Brand Reputation on Customer Satisfaction in Zakat Institution. International Journal of Supply Chain Management, 240-244.

Shaikh, I. A. (2018). The Foundations of Waqf Institutions: A Historical Perspective. Intellectual Discourse, 1213-1228.

Zain, R. A. (2017). Performance Measurement And Accountability Of Waqf Institutions In Malaysia. The 2016 4th International Conference on Governance and Accountability (2016 ICGA). France: EDP Sciences - Web of Conferences.

Zakari, M. S. (2015). Efficiency and effectiveness of waqf institutions in Malaysia: Toward financial sustainability. In Access to Finance and Human Development - Essays on Zakah, Awqaf and Microfinance (pp. 43-53). Qatar: Bloomsbury Qatar Foundation Journals. 